\title{
Disiplin Kerja terhadap Kinerja Karyawan
}

\section{Selfi Ariesni1*, Lise Asnur ${ }^{2}$}

1,2 Universitas Negeri Padang, Indonesia

\section{ART ICLE INFO}

\section{Article history:}

Received May 23, 2021

Revised May 29, 2021

Accepted September 14, 2021

Available online October 25, 2021

Kata Kunci:

Disiplin Kerja, Kinerja Karyawan

\section{Keywords:}

Work Discipline, Employee

Performance

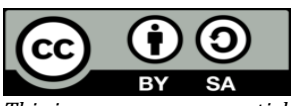

This is an open access article under the $\underline{C C}$ BY-SA license.

Copyright (C) 2021 by Author. Published by Universitas Pendidikan Ganesha.

\begin{abstract}
A B S T R A K
Kinerja karyawan belum sesuai dengan yang diharapkan, hal ini disebabkan adanya karyawan front office dan F\&B yang saat bekerja tidak berada ditempat, pergi keluar hotel dan baru kembali saat akan mengambil absen pulang. Penelitian ini bertujuan untuk menganalisis displin kerja terhadap kinerja karyawan. Pendekatan asosiatif kausal dengan bentuk penelitian kauntitatif adalah jenis penelitian yang dipakai pada penelitian ini. Teknik pengambilan sampel menggunakan total sampling dengan jumlah karyawan sebanyak 30 orang yang dijadikan sebagai populasi dan sampel pada penelitian ini. Jenis data yang digunakan dalam penelitian yaitu data primer melalui penyebaran kuesioner dan data sekunder dari absensi dan performance review karyawan. Metode pengumpulan data menggunakan angket. Teknik analisis data dengan uji persyaratan analisis dan juga pengujian hipotesis dengan teknik analisis regresi linear sederhana dan koefisien determinan dengan bantuan SPPS 20.00. Hasil penelitian menunjukkan displin kerja di kategori baik (50\%), kinerja karyawan di kategori tinggi $(63,33 \%$.). Uji regresi linear sederhana sebesar 12,494 nilai signifikan sig 0,007 < 0,05. Nilai $\mathrm{R}$ square 0,229. 22,9\% disiplin kerja dapat mempengaruhi kinerja karyawan dan $77,1 \%$ selebihnya yang mempengaruhi kinerja karyawan adalah faktor lain. Nilai t sebesar 007dengan nilai signifikan $0,007<0,05$ sehingga diperoleh adanya pengaruh yang signifikan antar kedua variabel. Pengujian koefisien regresi nilai 0,585 yang nilai signifikannya 0,007 < 0,05 dimana setiap satuan disiplin kerja dapat menaikkan 0,585 satuan kinerja karyawan. Maka, disiplin kerja berpengaruh terhadap kinerja karyawan.
\end{abstract}

\begin{abstract}
A BS TRACT
Employee performance has not been as expected, this is due to front office and F\&B employees who are not at work when they work, go out of the hotel and only return when they are going to take an absence home. This study aims to analyze work discipline on employee performance. Causal associative approach with quantitative research is the type of research used in this study. The sampling technique used was total sampling with a total of 30 employees who were used as the population and sample in this study. The types of data used in this study are primary data through questionnaires and secondary data from employee attendance and performance reviews. Methods of data collection using a questionnaire. The data analysis technique is by testing requirements analysis and also testing hypotheses with simple linear regression analysis techniques and determinant coefficients with the help of SPPS 20.00. The results showed that work discipline in the good category (50\%), employee performance in the high category (63.33\%.). Simple linear regression test of 12.494 significant value sig $0.007<0.05$. $R$ square value 0.229 . 22.9\% work discipline can affect employee performance and the remaining $77.1 \%$ that affect employee performance are other factors. The $t$ value is 007 with a significant value of 0.007 $<0.05$ so that there is a significant effect between the two variables. Testing the regression coefficient value of 0.585 with a significant value of $0.007<0.05$ where each work discipline unit can increase 0.585 employee performance units. So, work discipline affects employee performance.
\end{abstract}

\section{PENDAHULUAN}

Sektor pariwisata merupakan sektor yang mengalami perkembangan pesat saat ini. Hal ini membuat pemerintah pusat dan pemerintah daerah gencar mengembangkan sektor pariwisata di Indonesia. Keberhasilan dalam mengembangkan sektor pariwisata tidak dapat lepas dari sumber daya manusianya. Sumber daya manusia memegang peran yang sangat penting, sumber daya manusia dipandang sebagai faktor pendorong yang utama dalam menentukan keberhasilan suatu perusahaan (Dewi, 2021; Nabawi, 2019). Sumber daya manusia yang baik diharapkan akan menghasilkan kinerja yang baik sesuai dengan yang diharapkan dan diinginkan instansi (Farhah et al., 2020; Meilany \& Ibrahim, 2015; Rafiditya \& Syarifuddin, 2020). Sumber keberhasilan suatu perusahaan dalam menghasilkan kinerja yang tinggi adalah tenaga kerja yang berkualitas dan mempunyai efektifitas kerja yang memadai. Potensi sumber daya manusia mempunyai peranan yang sangat penting sebagai pelaku yang terlibat langsung dalam proses pembangunan industrial saat ini. Kinerja karyawan yang menghasilkan produk dengan kualitas dan 
kuantitas yang baik sesuai dengan standar akan mendapat kepercayaan masyarakat (Cahyadi, 2019; Rialmi, 2020). Salah satu penunjang dari industri pariwisata adalah disediakannya akomodasi penginapan seperti hotel. Hotel merupakan sebuah akomodasi yang mempergunakan sebagian atau keseluruhan bangunannya yang menyediakan pelayanan penginapan, makanan, minuman dan fasilitas penunjang lainnya bagi tamu yang dikelola untuk mencari keuntungan (Agus, 2011). Keberhasilan operasional hotel bergantung terhadap peranan sumber daya manusia didalamnya. Agar suatu perusahaan mengalami kemajuan, maka sumber daya manusia yang ada pada hotel harus memiliki visi dan misi yang sama dalam bekerja, yaitu meningkatkan pendapatan hotel. Hal ini dapat terjadi apabila sumber daya yang dimiliki hotel mempunyai kinerja yang baik.

Namun kenyataan saat ini, kinerja karyawan belum sesuai dengan yang diharapkan. (Cesilia et al., 2018; Nugraha \& Tjahjawati, 2018; Riyadi, 2015; Rofiliana \& Rofiuddin, 2021). Selain itu, motivasi kerja karyawan menurun yang disebabkan oleh berbagai faktor (Nurani \& Sarino, 2017; Purwanto, 2020). Selain itu, adanya karyawan front office dan F\&B yang saat bekerja tidak berada ditempat, pergi keluar hotel dan baru kembali saat akan mengambil absen pulang. Menurut beberapa karyawan housekeeping perilaku karyawan yang sering meninggalkan pekerjaan tersebut sudah tidak aneh lagi bagi karyawan lain. Seharusnya karyawan front office dan F\&B selalu stay ditempat kerja selama jam kerja berlangsung. Selain masalah diatas, juga ditemukan masalah lainnya yaitu adanya karyawan yang berkerja tidak sesuai dengan SOP hotel, seperti ada beberapa karyawan yang bermain handphone saat bekerja, ada karyawan food and beverage service yang memakai sendal ketika melayani pengantaran makanan kekamar tamu (room service), menghidangkan snack untuk peserta meeting, juga ketika berada diarea loby, serta karyawan housekeeping memakai sepatu olahraga dan bahkan ada yang memakai celana jeans saat bekerja. Padahal ini telah dilarang oleh pihak manajemen bahkan GM pun sudah membuat sebuah pengumuman resmi. Namun masih ada beberapa karyawan yang melanggarnya beberapa kali. Rangkayo Basa Hotel Padang Panjang merupakan salah satu hotel bintang dua (**) yang berada di Jl. Sutan Syahril No.411 - Silaing Bawah Padang Panjang Provinsi Sumatera Barat. Rangkayo Basa Hotel Padang Panjang merupakan salah satu hotel yang memperhatikan kinerja pegawainya dengan cara melakukan penilaian performance review sebagai evaluasi kinerja karyawan. Berikut data kinerja karyawan Rangkayo Basa Hotel Padang Panjang :

Tabel 1. Performance Review Recapitulation (2020)

\begin{tabular}{|c|c|c|c|c|c|}
\hline \multirow{2}{*}{ No } & \multirow{2}{*}{ Department } & \multicolumn{3}{|c|}{ Rank Value } & \multirow{2}{*}{ Total } \\
\hline & & Poor & Good & Great & \\
\hline 1. & HRD & & 1 & & 1 \\
\hline 2. & Accounting & & 2 & & 2 \\
\hline 3. & Sales \& marketing & & 1 & & 1 \\
\hline 4. & $\begin{array}{l}\text { Room Division (Front office, } \\
\text { Housekeeping ) }\end{array}$ & 2 & 11 & 1 & 14 \\
\hline 5. & $F \& B$ & 1 & 9 & & 10 \\
\hline 6. & Engineering & 1 & 1 & & 2 \\
\hline & Total & 4 & 25 & 1 & 30 \\
\hline
\end{tabular}

Berdasarkan performance review Recapitulation pada Tabel 1 diatas, dapat dilihat bahwa dari 30 karyawan Rangkayo Basa Hotel Padang Panjang terdapat karyawan yang berkategori Great (sangat baik) sebanyak 1, Good (Baik) sebanyak 25 orang dan berkategori Poor (Kurang) sebanyak 4 orang. Selain memperhatikan kinerja pegawainya Rangkayo Basa Hotel Padang Panjang juga memperhatikan memperhatikan disiplin kerja karyawannya. Namun masih ada karyawan yang belum mematuhi disiplin kerja, seperti ditemukannya bererapa karyawan yang sering datang terlambat saat bekerja. Berikut data keterlambatan karyawan Rangkayo Basa Hotel Padang Panjang pada bulan januari dan februari 2021 :

Tabel 2. Data keterlambatan karyawan Rangkayo Basa Hotel Padang panjang bulan Januari 2021

\begin{tabular}{lccccc}
\hline \multicolumn{1}{c}{ Bulan } & Jumlah karyawan & Terlambat & $\begin{array}{c}\text { Terlambat } \\
\text { \% }\end{array}$ & Terlambat lebih dari 3x & \% \\
\hline Januari & 30 & 6 & $20 \%$ & 2 & $6 \%$ \\
Februari & 30 & 5 & $16 \%$ & 2 & $6 \%$ \\
\hline
\end{tabular}

Pada 2 Tabel diatas dapat dilihat tingkat disiplin karyawan saat masuk kerja pada bulan januari dan bulan februari, pada bulan Januari terdapat sebanyak $20 \%$ karyawan yang datang terlambat dan $16 \%$ persen karyawan pada bulan Februari. Berdasarkan uaraian diatas masih ditemukannya karyawan yang datang melewati waktu yang telah ditentukan hotel. Keterlambatan karyawan tersebut banyak terjadi pada 
shift kerja pagi, dimana karyawan hotel terlambat setengah jam dari jam masuk kerja yang telah ditentukan. Masalah seperti diatas tidak bisa dibiarkan, apabila pihak manajemen tidak memperhatikan disiplin kerja maka akan berdampak buruk terhadap income hotel.

Disiplin kerja adalah sebuah perbuatan yang dilakukan oleh karyawan yang mana sesuai dengan peraturan tertulis maupun tidak tertulis dalam sebuah organisasi (Alhusaini et al., 2020; Cesilia et al., 2018; Darmawan, 2013). Kedisiplinan merupakan salah satu kunci terwujudnya tujuan perusahaan, karyawan dan masyarakat, dimana dengan disiplin kerja yang baik maka akan tumbuhnya kesadaran dalam diri karyawan untuk mengerjakan semua tugasnya dengan baik (Hasibuan, 2012; Rialmi, 2020). Ada beberapa indikator displin yaitu, ketepatan waktu datang ketempat kerja, ketepatan jam pulang kerumah, kepatuhan terhadap peraturan yang berlaku, penggunaan seragam kerja yang telah ditentukan, tangguang jawab dalam mengerjakan tugas dan melaksanakan tugas-tugas kerja sampai selesai setiap harinya (Mangkunegara \& Octorend, 2015). Peraturan kerja yang harus ditaati oleh semua karyawan mulai dari ketepatan masuk jam kerja, mengisi daftar hadir, ketepatan dalam menyelesaikan tugas yang diberikan oleh pimpinan, dan menciptakan suasana kerja yang tertib dan nyaman (Faustyna \& Jumani, 2018; Istiqomah \& Suhartini, 2016). Tindakan tidak disiplin (Indisipliner) akan berdampak pada pertumbuhan organisasi perusahaan. Disiplin dikatakan juga sebagai sarana untuk melatih dan mendidik orang-orang terhadap peraturan-peraturan agar ada kepatuhan dan supaya dapat berjalan dengan tertib dan teratur dalam organisasi (Sugawara \& Nikaido, 2014; Sutrisno et al., 2021). Peraturan perusahaan dibuat tentu bertujuan agar dapat dipatuhi oleh karyawan baik dari ketaatan karyawan dalam menepati waktu bekerja, ketaatan dalam mematuhi semua aturan yang ada dalam perusahaan, ketaatan terkait perilaku karyawan dalam menjalankan tugas dan kewajibannya, ketaatan karyawan dalam menjunjung tinggi norma hukum dan aturan lainnya. Jadi disiplin kerja yang tidak berjalan dengan baik akan berdampak pada kemajuan organisasi. Tanpa disiplin yang baik pada karyawan, sulit bagi organisasi untuk mencapai hasil yang optimal.

Hal inilah menjadi salah atu alasan mengapa penelitian yang bertujuan menganalisis pengaruh disiplin kerja terhadap kinerja karyawan. Mengetahui kondisi disiplin karyawan akan memberikan gambaran bagaimana kinerja karyawan dalam menjalankan tugas. Gambaran yang jelas tentang bagaimana kedisiplinan kerja digunakan untuk memperbaiki kinerja karyawan dalam menjalankan tugasnya. Penelitian tentang hubungan disiplin kerja terhadap kinerja karyawan sudah banyak dilakukan. Dari penelitian tersebut ditemukan disiplin kerja memberikan pengaruh terhadap perusahaan (Izzah \& Ardiani, 2018; Kusmiyatun \& Sonny, 2021; Rahmayanti et al., 2021). Tujuan penelitian ini untuk menganalisis pengaruh disiplin kerja terhadap kinerja karyawan. Adanya penelitian ini diharapkan dapat membantu memperbaiki kinerja karyawan.

\section{METODE}

Penelitian ini tergolong kepada penelitian kuantitatif menggunakan pendekatan asosiatif kausal dengan cara menyebarkan angket atau kuesioner untuk semua karyawan Rangkayo Basa Hotel Padang Panjang yang mana kuisioner/angket tersebut akan diisi oleh HOD setiap departemen dan GM. Metode total sampling merupakan metode pengambilan sampel pada penelitian ini. Total sampling merupakan teknik pengambilan sampel di mana jumlah sampel sama dengan populasi(Sugiyono, 2017). Jumlah sampel penelitian ini adalah seluruh karyawan Rangkayo Basa Hotel Padang Panjang sebanyak 30 orang. SPSS 20.00 menjadi aplikasi yang digunakan untuk menentukan besaran pengaruh antar variabel. Uji normalitas, uji homogenitas, uji linearitas dan uji hipotesis regresi linear sederhana menjadi cara guna membuktikan data.

\section{HASIL DAN PEMBAHASAN}

\section{Hasil}

Hasil analisis data dengan jumlah jumlah 30 responden terkait variabel disiplin kerja karyawan Rangkayo Basa Hotel Padang Panjang yang didapat melalui 13 pernyataan, peneliti mendapatkan hasil dengan menggunakan bantuan SPSS 20.00, hasil yang didapatkan dijabarkan melalui tabel sebagai berikut :

Tabel 3. Distribusi Frekuensi Variabel Disiplin Kerja(X)

\begin{tabular}{cccc}
\hline Kategori & Kelas Interval & Frekuensi & \% \\
\hline Sangat Baik & $\geq 52,48$ & 13 & 43,33 \\
\hline Baik & $\geq \mathbf{4 3 , 4 9 - < \mathbf { 5 2 , 4 8 }}$ & $\mathbf{1 5}$ & $\mathbf{5 0}$ \\
\hline Cukup Baik & $\geq 34,51-<43,49$ & 2 & 6,67 \\
\hline
\end{tabular}




\begin{tabular}{cccc}
\hline Kategori & Kelas Interval & Frekuensi & $\mathbf{\%}$ \\
\hline Buruk & $\geq 25,52-<34,51$ & 0 & 0 \\
Sangat Buruk & $<25,52$ & 0 & 0 \\
\hline Jumlah & & $\mathbf{3 0}$ & $\mathbf{1 0 0}$ \\
\hline
\end{tabular}

Berdasarkan Tabel 3 tersebut dijelaskan bahwa dari 30 orang responden untuk variabel Disiplin Kerja (X) dapat dikelompokkan sebagai berikut: Kategori sangat baik menunjukan sebanyak 43,33\%, Kategori baik menunjukan sebanyak 50\%, Kategori cukup menunjukan sebanyak 6,67\%, Kategori buruk menunjukan sebanyak 0\%, Kategori sangat buruk menunjukan sebanyak 0\%. Berdasarkan perhitungan statistik variabel Disiplin Kerja (X) berada pada klasifikasi skor $\geq 43,49-<52,48$ menunjukan kategori baik dengan persentase 50\%. Penelitian selanjutnya dilakukan kepada 30 responden tentang variabel Kinerja Karyawan. Hasil yang didapatkan dijabarkan pada tabel dibawah:

Tabel 4. Distribusi Frekuensi Variabel Kinerja Karyawan (Y)

\begin{tabular}{cccc}
\hline Kategori & Kelas Interval & Frekuensi & \% \\
\hline Sangat Baik & $\mathbf{2 6 7 , 9 9}$ & $\mathbf{1 9}$ & $\mathbf{6 3 , 3 4}$ \\
\hline Baik & $\geq 56,66-<67,99$ & 10 & 33,33 \\
Cukup Baik & $\geq 45,33-<56,66$ & 1 & 3,33 \\
Buruk & $\geq 34-<45,33$ & 0 & 0 \\
Sangat Buruk & $<34$ & 0 & 0 \\
\hline Jumlah & & $\mathbf{3 0}$ & $\mathbf{1 0 0}$ \\
\hline
\end{tabular}

Dari Tabel 4 di atas dijelaskan bahwa dari 30 orang responden untuk variabel Kinerja Karyawan (Y) dapat dikelompokkan sebagai berikut: Kategori sangat baik menunjukan sebanyak 63,34\%, Kategori baik menunjukan sebanyak 33,33\%, Kategori cukup menunjukan sebanyak 3,33\%, Kategori buruk menunjukan sebanyak 0\%, Kategori sangat buruk menunjukan 0\%. Berdasarkan perhitungan statistik variabel Kinerja Karyawan (Y) berada pada klasifikasi skor $\geq 67,99$ menunjukan kategori tinggi dengan persentase 63,34\%. Hasil uji hipotesis dengan regresi linear sederhana melalui uji persyaratan analisis yaitu uji normalitas menggunakan kolmogorov smirnov test nilai signifikan untuk variabel disiplin kerja (X) adalah 0,562 dan untuk variabel kinerja karyawan (Y) nilai signifikan yang didapatkan adalah 0,484. Dengan nilai sig > dari 0,05, maka didapatkan hasil bahwa kedua data terdistribusi normal. Uji Homogenitas menggunakan Test homogenity of variance dengan nilai signifikan adalah 0,072 dengan taraf signifikansi > 0,05 . Sehingga diambil kesimpulan bahwa data berasal dari populasi yang mempunyai varians yang sama atau data bersifat homogeny dan uji linearitas didapatkan hasil dengan nilai signifikan 0,966 dengan taraf signifikansi > 0,05 sehingga diambil kesimpulan bahwa kedua variabel tersebut terdapat hubungan linear secara signifikan.

Tabel 5. Hasil Signifikan Uji F

\begin{tabular}{clccccc}
\hline & Model & Sum of Squares & df & Mean Square & F & Sig. \\
\hline \multirow{2}{*}{1} & Regression & 279,785 & 1 & 279,785 & 8,338 & 0,007 \\
& Residual & 939,582 & 28 & 33,556 & & \\
\cline { 2 - 7 } & Total & $\mathbf{1 2 1 9 . 3 6 7}$ & $\mathbf{2 9}$ & & & \\
\hline
\end{tabular}

Dari Tabel diatas diperoleh nilai F 8,338 dengan sig 0,007<0,05 sehingga dapat disimpulkan bahwa Ha diterima dan $\mathrm{HO}$ ditolak dan terdapat pengaruh yang positif dan signifikan antara disiplin kerja dengan kinerja karyawan di Rangkayo Basa Hotel Padang Panjang. Dari Tabel diatas diperoleh koefisien regresi sebesar 0.585 dengan nilai sig 0,007 < 0,05. Artinya dimana setiap peningkatan satuan disiplin kerja akan meningkatkan 0.585 satuan kinerja karyawan.

Tabel 6. Hasil Uji Koefisien Regresi Sederhana

\begin{tabular}{llccccc}
\hline \multirow{2}{*}{ Model } & \multicolumn{2}{c}{ Unstandardized Coefficients } & \multirow{2}{*}{$\begin{array}{c}\text { Standardized } \\
\text { Coefficients }\end{array}$} & \multirow{2}{*}{ t } & Sig. \\
\cline { 3 - 6 } & & B & Std. Error & Beta & & \\
\hline \multirow{2}{*}{1} & (Constant) & 39,785 & 10,253 & & 3,880 & 0,001 \\
& Disiplin Kerja & 0,585 & 0,203 & 0,479 & 2,888 & 0,007 \\
\hline
\end{tabular}


Tabel 7. Hasil Koefisien Determinasi (R Square)

\begin{tabular}{ccccc}
\hline Model & R & R Square & Adjusted R Square & Std. Error of the Estimate \\
\hline 1 & 0,479 & 0,229 & 0,202 & 5,79280 \\
\hline
\end{tabular}

Dari Tabel diatas diperoleh nilai R square sebesar 0,229, jadi hal ini berarti variabel disiplin kerja berpengaruh sebesar 22,9\% terhadap kinerja karyawan di Rangkayo Basa Hotel Padang Panjang dan 77,1\% dipengaruhi oleh variabel lainnya.

\section{Pembahasan}

Temuan pertama diperoleh hasil penelitian yang di lakukan di Rangkayo Basa Hotel Padang Panjang, dapat dijabarkan dari 30 responden maka variabel disiplin kerja dapat dikategorikan baik 50\%, kemudian pada indikator selalu datang dan pulang tepat waktu 53,33\% responden mengatakan sangat baik, pada indikator mengerjakan semua pekerjaan dengan baik responden mengatakan sangat baik 66,67\%, dan pada indikator mematuhi semua peraturan organisasi dan norma-norma yang berlaku dikategorikan sangat baik 53,34\%. Artinya berdasarkan penelitian yang telah dilakukan, diperoleh hasil didiplin kerja di Rangkayo Basa Hotel Padang Panjang termasuk dalam kategori sangat baik. Kedisiplinan merupakan salah satu fungsi manajemen SDM yang terpenting yang mana merupakan kunci untuk terwujudnya sebuah tujuan karena tanpa disiplin yang baik, akan sulit terwujudnya sebuah tujuan secara maksimal (Hasibuan, 2012; Istiqomah \& Suhartini, 2015). Displin kerja sangatlah penting bagi perusahaan, karena disiplin kerja merupakan sebuah sarana yang digunakan untuk melatih kepribadian karyawan agar mengahasilkan kinerja yang berkualitas. Penerapan disiplin kerja tidak hanya bermanfaat untuk mencapai tujuan dalam suatu organisasi melainkan juga bermanfaat untuk mendorong dan menggerakkan pegawai sehingga menumbuhkan semangat kerja dan gairah kerja pegawai (Tyas \& Sunuharyo, 2018). Sehingga tenaga kerja atau pegawai yang bekerja secara disiplin dan mematuhi peraturan serta visi misi organisasi akan memiliki kinerja yang baik.

Temuan kedua, diperoleh bahwa dari 30 responden maka variabel kinerja karyawan dapat dikatogerikan sangat baik 63,33\%. Kemudian pada indikator kualitas kerja 50\% responden mengatakan sangat baik, pada indikator kuantitas kerja 66,66\% responden mengatakan sangat baik, pada indikator tanggung jawab 83,33\% responden mengatakan sangat baik, pada indikator kerjasama 86,66\% responden mengatakan sangat baik, dan pada indikator inisiatif $90 \%$ responden mengatakan sangat baik.. Artinya kinerja karyawan di Rangkayo Basa Hotel Padang Panjang termasuk dalam kategori sangat baik. Kinerja ialah hasil kerja karyawan yang dilihat dari segi kualitas, kuantitas, waktu kerja, dan kerja sama untuk mencapai suatu tujuan yang telah ditetapkan sebelumnya (Edy, Sutrisno, 2016; U. D. Suherman, 2018). Kinerja karyawan yang menghasilkan produk dengan kualitas dan kuantitas yang baik sesuai dengan standar akan mendapat kepercayaan masyarakat (Cahyadi, 2019; Rialmi, 2020). Jadi kinerja karyawan sangat penting. Jika kinerja karyawan disuatu perusahaan baik, maka perusahaan tersebut akan terus berkembang dan tujuan dari perusahaan yang telah ditentukan sebelumnya akan terwujud.

Temuan ketiga, dari hasil uji hipotesis yang dilakukan dengan bantuan SPSS 20.00 diperoleh nilai koefisien determinasi R Square 0,229, artinya pengaruh variabel X terhadap variabel Y adalah sebesar 0,229 $(22,9 \%)$. Sedangkan $77,1 \%$ dipengaruhi oleh faktor lain. Maka hipotesis yang diterima dalam penelitian ini adalah Ha, sedangkan HO ditolak. Disiplin kerja berpengaruh terhadap kinerja karyawan karena disiplin kerja adalah salah satu faktor-faktor yang mempengaruhi kinerja karyawan. Adapun koefisien regresi diperoleh sebesar 0.585 dengan nilai sig 0,007 <0,05. Artinya setiap peningkatan sebesar 1 satuan disiplin kerja akan meningkatkan 0.585. Satuan kinerja karyawan. semakin tinggi disiplin kerja yang kondusif maka akan menyebabkan semakin tingginya prestasi kerja. Sebaliknya, semakin rendah disiplin kerja yang kondusif akan menyebabkan semakin rendahnya prestasi kerja (Mandey \& Sahangggamu, 2014; H. Suherman, 2018). Apabila karyawan telah memiliki kedisiplinan serta kepatuhan dalam mentaati peraturan dan keputusan yang telah menjadi kesepakatan bersama dari perusahaan, maka karyawan tersebut akan merasa senang dengan pekerjaannya karena karyawan mampu menyelesaikan pekerjaannya dengan baik dan benar sehingga diharapkan akan timbul rasa loyalitas dari para karyawan kepada perusahaan (Sari \& Masruroh, 2018; Sugawara \& Nikaido, 2014). Jadi dapat diambil kesimpulan bahwa semakin tinggi disiplin kerja karyawan maka semakin bagus juga kinerja karyawan di Rangkayo Basa Hotel Padang Panjang. Temuan ini diperkuat dengan temuan sebelumnya yang menyatakan adanya pengaruh yang signifikan antara disiplin kerja terhadap kinerja karyawan (Sugawara \& Nikaido, 2014).temuan lain juga menyatakan disiplin kerja memberikan pengaruh terhadap perusahaan (Izzah \& Ardiani, 2018; Kusmiyatun \& Sonny, 2021; Rahmayanti et al., 2021). Jadi, disiplin kerja dan kenerja karyawan adalah dua hal yang tidak bisa dipisahkan. Disiplin yang baik akan menghasilkan sebuah kinerja karyawan yang baik juga yang tentunya akan mempengaruhi pengahasilan suatu perusahaan. Hasil penelitian ini diperoleh bahwa masih 
dibutuhkan sebuah program supervise untuk meningkatakan kinerja guru dalam menyelesaikan tugas yang diberikan.

\section{SIMPULAN}

Disiplin kerja yang baik dalam kegiatan sehari-hari akan mempengaruhi kinerja karyawan dalam menjalakan tugas. Jika disiplin baik maka kinerja karyawan baik yang secara langsung mempengaruhi kualitas sumber daya manusia pada suatu perusahan. Untuk meningkatakan kinerja karyawan, disiplin kerja harus ditingkatkan untuk membantu dalam menjalankan tugas.

\section{DAFTAR PUSTAKA}

Agus, S. (2011). Manajemen Penyelenggaraan Hotel. Alfabeta.

Alhusaini, A., Kritiawan, M., \& Eddy, S. (2020). Pengaruh Motivasi Kerja Dan Disiplin Kerja Terhadap Kinerja Guru.Jurnal Pendidikan Tambusai, 4(3), 2166-2172. https://doi.org/10.36709/jopspe.v5i1.13326.

Cahyadi, B. (2019). Pengaruh Gaya Kepemimpinan Dan Lingkungan Kerja Terhadap Kinerja Karyawan Dalam Perspektif Islam. Amwaluna: Jurnal Ekonomi Dan Keuangan Syariah, 3(1), 29-40. https://doi.org/10.29313/amwaluna.v3i1.4141.

Cesilia, K. A., Tewal, B., \& Tulung, J. E. (2018). Pengaruh Disiplin Kerja, Perencanaan Karir Dan Kompetensi Terhadap Kinerja Karyawan Kantor Pelayanan Pajak (KPP) Pratama Manado. Jurnal EMBA: Jurnal Riset Ekonomi, Manajemen, Bisnis Dan Akuntansi, 6(1), 426-434. https://doi.org/10.35794/emba.v6i1.19153.

Darmawan, D. (2013). Prinsip-prinsip Perilaku Organisasi. PT. Temprina Media Grafika.

Dewi, N. N. (2021). Pengaruh Motivasi Disiplin Kerja Dan Pengawasan Terhadap Kinerja. Aksara: Jurnal Ilmu Pendidikan Nonformal, 7(2), 355. https://doi.org/10.37905/aksara.7.2.355-366.2021.

Edy, Sutrisno. (2016). Manajemen Sumber Daya Manusia. Kencana Prenada Media Group.

Farhah, A., Ahiri, J., \& Ilham, M. (2020). Pengaruh Motivasi Kerja Dan Disiplin Kerja Terhadap Kinerja Karyawan. Jurnal Online Program Studi Pendidikan Ekonomi, 5(1), 1. https://doi.org/10.36709/jopspe.v5i1.13326.

Faustyna, \& Jumani. (2018). Pengaruh Pengembangan Karir Dan Disiplin Kerja Terhadap Kinerja Karyawan Pada PT. Pelabuhan Indonesia I (Persero) Medan. Jurnal Ilmiah Manajemen Dan Bisnis, 15(1). https://doi.org/10.30596/jimb.v15i1.970.

Hasibuan, M. (2012). Manajemen Sumber Daya Manusia. PT.Bumi Aksara.

Istiqomah, S. N., \& Suhartini. (2016). Pengaruh Disiplin Kerja dan Iklim Komunikasi terhadap Kinerja Pegawai Dinas Perhubungan Kota Yogyakarta, dengan Motivasi Kerja sebagai Variabel Intervening. Jurnal Siasat Bisnis, 19(1), 89 - 97. https://doi.org/10.20885/jsb.vol19.iss1.art8.

Istiqomah, S. N., \& Suhartini, S. (2015). Pengaruh Disiplin kerja dan Iklim Komunikasi Terhadap kinerja pegawai Dinas Perhubungan Kota Yogyakarta, dengan motivasi kerja sebagai variabel intervening. Jurnal Siasat Bisnis, 19(1), 89-97. https: //doi.org/10.20885/jsb.vol19.iss1.art8.

Izzah, N., \& Ardiani, I. (2018). Pengaruh Kompensasi Dan Disiplin Kerja Terhadap Produktivitas Kerja Karyawan Pada Mechanical Division PT Mulia Makmur Elektrikatama. Majalah Ilmiah Bijak, 13(2), 210-222. https://doi.org/10.31334/bijak.v13i2.78.

Kusmiyatun, S. D., \& Sonny, S. (2021). Pengaruh Lingkungan Kerja Dan Disiplin Kerja Terhadap Kinerja Karyawan Pada Pt Gapuraning Rahayu Ciamis. Jurnal Renaissance, 6(1), 741. https://doi.org/10.53878/jr.v6i1.139.

Mandey, S., \& Sahangggamu, P. (2014). Pengaruh Pelatihan Kerja, Motivasi, Dan Disiplin Kerja Terhadap Kinerja Karyawan Pada Pt. Bank Perkreditan Rakyat Dana Raya. Jurnal Riset Ekonomi, Manajemen, Bisnis Dan Akuntansi, 2(4), 514-523. https://doi.org/10.35794/emba.v2i4.6359.

Mangkunegara, A. P., \& Octorend, T. R. (2015). Effect of Work Discipline, Work Motivation and Job Satisfaction on Employee Organizational Commitment in the Company (Case Study in PT. Dada Indonesia). Universal Journal of Management, 3(8), 318-328. https: //doi.org/10.13189/ujm.2015.030803.

Meilany, P., \& Ibrahim, M. (2015). Pengaruh Disiplin Kerja Terhadap Kinerja Karyawan (PT. Indah Logistik Cargo). Jurnal FISIP, 2(2015), 1-11. https://jom.unri.ac.id/index.php/JOMFSIP/article/view/5762.

Nabawi, R. (2019). Pengaruh Lingkungan Kerja, Kepuasan Kerja dan Beban Kerja Terhadap Kinerja Pegawai. Maneggio: Jurnal Ilmiah Magister Manajemen, 2(2), 170-183. https://doi.org/10.30596/maneggio.v2i2.3667.

Nugraha, A., \& Tjahjawati, S. S. (2018). Pengaruh Kompensasi Terhadap Kinerja Karyawan. Jurnal Riset 
Bisnis Dan Investasi, 3(3), 24. https://doi.org/10.35697/jrbi.v3i3.942.

Nurani, R. T., \& Sarino, A. (2017). Kepemimpinan Kepala Sekolah , Supervisi Akademik, dan Motivasi Kerja dalam Meningkatkan Kinerja Guru. Jurnal Pendidikan Manajemen Perkantoran, 2(1), 298. https://doi.org/10.17509/jpm.v2i1.14613.

Purwanto, A. (2020). Studi eksplorasi Dampak WFH Terhadap Kinerja Guru. Journal of Education, Psychology and Counseling, 2(1), 92-100. https://ummaspul.ejournal.id/Edupsycouns/article/view/397.

Rafiditya, A., \& Syarifuddin. (2020). Pengaruh Self Esteem dan Self Efficacy terhadap Kinerja Karyawan PT Dana Tabungan dan Asuransi Pegawai Negeri Kantor Cabang Utama Bandung. E-Procceding of Management, 7(2), 4143-4150.

Rahmayanti, R., Haryati, T., Miyono, N., \& Safitri, A. (2021). Pengaruh Kompetensi Profesional, Motivasi Kerja dan Disiplin Kerja terhadap Kinerja Guru Sekolah Menengah Atas Negeri se-Kabupaten Pemalang. Jurnal Manajemen Pendidikan: Jurnal Ilmiah Administrasi, Manajemen Dan Kepemimpinan Pendidikan, 3(1), 43-55. https://doi.org/10.21831/jump.v3i1.35791.

Rialmi, Z. (2020). Pengaruh Kedisiplinan Terhadap Kinerja Karyawan Pada PT. Bhakti Karya Distribusi Indonesia. JENIUS (Jurnal Ilmiah Manajemen Sumber Daya Manusia), 3(3), 286-293. https://doi.org/10.32493/JJSDM.v3i3.4866.

Riyadi, B. A. (2015). Pengaruh Pengalaman Kerja Terhadap Kinerja Karyawan Pada Toko Emas Semar Nganjuk. Jurnal Equilibrium, 3(1), 49-61. https://doi.org/10.25273/equilibrium.v3i1.637.

Rofiliana, L., \& Rofiuddin, M. (2021). Faktor-faktor yang mempengaruhi kinerja karyawan Bank Syariah Indonesia. Journal of Management and Digital Business, 1(1), 1-12. https: //doi.org/10.53088/jmdb.v1i1.26.

Sari, M., \& Masruroh, F. (2018). Pengaruh Motivasi Dan Disiplin Kerja Terhadap Kinerja Pegawai Di Kecamatan Magelang Tengah Kota Magelang. Jurnal Mahasiswa Administrasi Negara (JMAN), 02(02), 36-51. http://jom.untidar.ac.id/index.php/jman/article/view/335.

Sugawara, E., \& Nikaido, H. (2014). Properties of AdeABC and AdeIJK efflux systems of Acinetobacter baumannii compared with those of the AcrAB-TolC system of Escherichia coli. Antimicrobial Agents and Chemotherapy, 58(12), 7250-7257. https://doi.org/10.1128/AAC.03728-14.

Sugiyono. (2017). Metode Penelitian Kuantitatif, Kualitatif, dan R\&D. Alfabeta.

Suherman, H. (2018). Pengaruh Gaya Kepemimpinan Dan Disiplin Kerja Terhadap Kinerja Karyawan PT. Selaras Karya Raya Jakarta. JENIUS (Jurnal Ilmiah Manajemen Sumber Daya Manusia), 2(1), 1-14. https://doi.org/10.32493/jjsdm.v2i1.1932.

Suherman, U. D. (2018). Pengaruh Pendidikan Dan Pelatihan Terhadap Kinerja Karyawan Bni Syariah Cabang Bandung. JISPO Jurnal Ilmu Sosial Dan Ilmu Politik, 6(2), 1-8. http://journal.uinsgd.ac.id/index.php/jispo/article/view/3799.

Sutrisno, Yanurianto, \& Indrawan, Y. W. (2021). Pengaruh Pelatihan Dan Disiplin Kerja Terhadap Kinerja Karyawan Pada PT. Pratama Abadi Industri Di Tangerang. EFEKTIF, 3(4), 464 - 474. https://doi.org/10.32493/JEE.v3i4.11282.

Tyas, R. D., \& Sunuharyo, B. S. (2018). Pengaruh Disiplin Kerja Dan Lingkungan Kerja Terhadap Kinerja Karyawan (Studi Pada Karyawan PT. Pertamina (Persero) Refinery Unit IV Cilacap). Jurnal $\begin{array}{lll}\text { Administrasi } \quad \text { Bisnis, } & 62(1), & 172-180 .\end{array}$ http://administrasibisnis.studentjournal.ub.ac.id/index.php/jab/article/view/2662. 